\title{
Managing chronic disease: a case study of an innovative role in respiratory nursing practice
}

Sonja Mcllfatrick and Felicity Hasson Institute of Nursing Research, School of Nursing, University of Ulster, UK, Hugh P. McKenna Faculty of Life and Health Sciences, University of Ulster, UK, Sinead Keeney Institute of Nursing Research, School of Nursing, University of Ulster, UK, Marlene Sinclair and Brenda Poulton Institute of Nursing Research, University of Ulster, UK

\begin{abstract}
Background: The increased incidence of chronic disease in recent years represents a significant challenge for the National Health Service. This coupled with substantial reforms in recent years has resulted in many changes in the delivery of healthcare, such as the proliferation of new nursing and midwifery roles. One such role is the Respiratory Nurse Specialist. Aims: The aim of this paper is to explore the role of the RNS from the post-holder and service perspective. This includes examining the organizational infrastructure, working relationships, career paths, perceived benefits and enablers and barriers required to make this role successful. Methods: A naturalistic case study methodology was adopted and a variety of data collection approaches were used. These included semi-structured interviews with the post-holder, line manager and Director of Finance, non-participant observation of practice, review of job description, audit data and other relevant documentation relating to the post. Findings: Findings revealed evidence of the role being innovative and effective. These related to the role context; role delivery, skills and knowledge required; the personal characteristics of the post-holder, the impact on multidisciplinary integrated working and the response to the needs of patients and communities. Conclusions: This case study illustrates the value and potential of nurses to lead and co-ordinate the care for patients with chronic diseases, and specifically the provision of a high-quality respiratory service.
\end{abstract}

Keywords: chronic disease; primary care; respiratory nurse specialist; role clarification; specialist practice

Received: November 2005; accepted: March 2007

\section{Introduction}

The World Health Organization (WHO) identified that chronic disease will be the leading cause of disability by 2020 , becoming the most expensive problem for health care systems (WHO, 2002). Respiratory diseases are one of the most common forms of ill health. In response, recent policy and practice initiatives recognize the need to improve

Address for correspondence: Dr Sonja McIlfatrick, Institute of Nursing Research and School of Nursing, University of Ulster, Shore Road, Newtownabbey, BT37 0QB, UK. Email: sj.mcilfatrick@ulster.ac.uk

(C) 2007 Cambridge University Press standards of care and increase choice for patients with long-term conditions (Department of Health, 2006). Changes, however, in health service delivery and workforce structure mean that nursing roles are changing. For example, the role of the respiratory nurse specialist (RNS) has changed dramatically during the past 10 years. This is a result of an increase in skills and expertise of nurses and pressures to improve patient access to appropriate services (Rafferty and Elborn, 2002).

Mills et al. (2002) noted that specialist nursing is emerging as a key component within the National Health Service (NHS), especially for the care of patients with chronic conditions. While the 
proliferation of innovative nursing and midwifery roles in the UK have been the topic of much debate (Kendall and Lissauer, 2003), there is a dearth of research into their introduction, prevalence and effectiveness (Buchan and Dal Poz, 2002). This paper reports on an in-depth case study of a communitybased respiratory nursing specialist, employed in an integrated acute and community health care organization in Northern Ireland. It aims to provide insight into the role of a respiratory nurse from the postholder and management perspective through examining the organizational infrastructure, working relationships, career paths and enablers, and inhibiting factors for the role. This study is part of a larger research project undertaken in 2004 on innovative nursing and midwifery roles (McKenna et al., 2005).

\section{Background}

In the UK, respiratory disease kills one in four people and accounts for more deaths each year than coronary artery disease or non-respiratory cancer (British Thoracic Society, 2001). The cost of treatment in the UK is high, with over a quarter of a million emergency admissions for respiratory diseases in 1999-2000 (Lung Asthma Information Agency, 2001). Despite the considerable burden imposed on patients, the health service and society, respiratory diseases have not been seen as a priority until recently (Department of Health, 2006).

The incidence of respiratory diseases over recent years has provided an opportunity for specialist nursing roles to be developed worldwide (Madonna and Keating, 1999; Ross, 1999; Chang and Wong, 2001; Nolan et al., 2002; Nkowane and Saxena, 2004). This proliferation of innovative nursing roles has been driven by waiting list initiatives (Read et al., 2001), patient demands for greater choice and accessibility (Daly and Carnwell, 2003), nurse prescribing (Last and Self, 1994), the reduction in junior doctors' hours of work and the introduction of the European Working Time Directive (WTD) (Cameron and Masterson, 2000; Buchan and Seccombe, 2003), and an increasing emphasis on interagency and inter professional working (Department of Health, 2000; Fitzgerald et al., 2003).

There is much confusion and disagreement regarding the scope of practice of new roles (Jamieson and Williams, 2002; Turner and Keyzer, 2002). In addition, there have been warnings that innovative roles can lead to isolation and 'burnout', especially when there is minimal support within the organization (Scholes et al., 1999; Wilson-Barnett et al., 2000; Ewens, 2003). The innovative nature of some roles can mean that accessibility to colleagues in similar roles is difficult, limiting opportunities to discuss professional and practice issues, or identify possible mentors (Levenson and Vaughan, 1999). Moreover, the effect of work environment (eg high job demands, little support from peers, lack of essential resources) on role stress/role strain in nursing has been acknowledged (Lambert and Lambert, 2001). With this confusion surrounding role development and professional isolation, there is a potential for post-holders who are involved in innovative role development to experience role stress and conflict.

Role conflict is defined as divergence between the role expectations among different members of the role set (Bower et al., 2004). Bower et al. (2004) studied the introduction of a new primary health care role and concluded that the specification of the post-holder in the new role and the expectations among existing staff increased the potential for role conflict. In Northern Ireland, McKenna et al. (2003) investigated professional and lay views in relation to generic and specialist roles in the community and noted that there was concern that specialization (while welcome) would lead to role conflict, role overlap and role confusion. Pearson (2003) argued that role confusion and conflict have become endemic in nursing for a number of reasons. He concluded that although the contribution of nursing is difficult to define in an evolving profession, the rethinking of role boundaries has never been as important as it is now.

\section{Respiratory nurse specialist}

Early research into respiratory health worker roles found that nurses visiting respiratory patients at home as part of the home care team helped patients to survive longer (Cockcroft et al.,1987). In this study it was seen that the nurses focused on health education and support rather than merely disease management. The authors, however, indicate that whilst such an approach to care is beneficial it is costly to the health service.

More recently the role of the specialist nurse in chronic disease management has broadened and they are now recognized as valuable members of the multidisciplinary team (Wooler, 2001). The role of 
the nurse specialist encompasses education, support, organization of care and the application of research (Wilson-Barnett and Beech, 1994). Although Rafferty and Elborn (2002) reported that it was difficult to prove which outcomes were directly attributable to the activity of RNS, there are many examples of how the RNS has led to improved outcomes for patients with chronic disease. For example, Ketelaars et al. (1996) reported that specialist community nurses demonstrated a higher clinical competence in the care of patients with chronic obstructive pulmonary disease (COPD). Sharples et al. (2002) undertook a randomized controlled trial of nurse practitioner versus doctor-led outpatient care in a bronchiectasis clinic and found better health-related quality of life ratings for the nurse-led care. Horrocks et al. (2002), in a systematic review in primary care, concluded that the nurse practitioner could provide care that is of a similar or better quality than that provided by general practitioners (GPs). While Griffiths et al. (2004) reported that asthma specialist nurses using a liaison model of care reduced unscheduled care for asthma in a deprived multiethnic health district, more recently, Laroche (2005) investigated if an RNS could effectively and safely follow up patients admitted to hospital with asthma. She concluded that follow up of outpatients' visits could be delivered as effectively and safely by an appropriately trained RNS as by a respiratory consultant. Yet, Taylor et al.'s (2005) systematic review of evidence on the effectiveness of nurse-led innovations for patients with COPD concluded that there was little data to conclude clinically relevant benefits or harm arising from such interventions.

However, it is acknowledged that an expansion of the RNS's responsibilities brings increased autonomy and accountability (Rafferty and Elborn, 2002) and they must therefore be equipped with the necessary skills and knowledge to perform this role. It has also been suggested that the clinical and theoretical knowledge requirements of specialist nurses have outpaced many current nurse education programmes, resulting in practitioners seeking training from medical colleagues and in-house teaching sessions (Wooler, 2001).

\section{Methodology}

The aim of this paper was to explore the role of the RNS, examining the organizational infrastructure, working relationships, career paths and perceived benefits of this role from both the post-holder and management perspective. In order to achieve this aim a case study approach was adopted.

Yin $(1994,13)$ defined a case study as:

An empirical enquiry that investigates a contemporary phenomenon within its real life context, when the boundaries between phenomenon and context are not clearly evident, and in which multiple sources of evidence are used.

A case study has been described as being simultaneously descriptive, exploratory and explanatory. Mills et al. (2002) noted that case studies are useful, particularly where there is a dearth of research, as in this case on the experience and difficulties faced by a specialist nurse providing a new service. Purposive sampling was employed and the participants were selected from a list of innovative post-holders identified by Executive Directors of Nursing in an earlier part of the main study (See McKenna et al., 2005).

\section{Sample}

The sample for this study consisted of the RNS, the post-holder's line manager and Director of Finance. The post-holder's line manager and Director of Finance were included in order to capture a managerial perspective and document the organizational infrastructure, working relationships and enabling and inhibiting factors for the role.

\section{Data collection methods}

Within the case study a variety of data collection methods were used. These included: semi-structured one-to-one interviews with the post-holder and with her line manager and Director of Finance, nonparticipant observation of practice, review of job descriptions and other relevant documents relating to the post, and an examination of available audit data. All the interviews were audio-taped and transcribed verbatim. The length of the interviews ranged from twenty to eighty minutes.

The non-participant observation involved the researcher shadowing the post-holder while the latter was going about her usual duties. Stake (1995)

Primary Health Care Research \& Development 2007; 8: 251-263 
noted that observation requires keeping a good record of events in order to provide a relatively incontestable description for further analysis and reporting. For the present study two distinct aspects of the participant's role were observed: a nurse-led assessment clinic (four hours) and a pulmonary rehabilitation programme (three hours). Denzin (1989) suggested that observation records should contain explicit reference to participants, interactions, routines, rituals, temporal elements, interpretations and social organization. Therefore, the researcher kept field notes of all activities undertaken. Observation of the post-holder recorded the following:

- A description of the activity.

- The post-holder's approach to the activity.

- An outline of how this practice was innovative.

- Potential benefits to patients.

- Any thoughts/perceptions of the interaction/ activity.

\section{Data analysis}

The interview transcripts were subjected to thematic content analysis using the guidelines described by Burnard (1991; 1996). For example, each transcript was read a number of times and organized into general themes. This thematic framework was based upon the aims of the study and the interview topics. Categories of data were allocated to each theme and finally meaning units were identified for each category. Member checking of these themes was undertaken with all the participants of the study.

\section{Ethical considerations}

Prior to commencement of the study, ethical approval was given on the project by the Office for Research Ethics for Northern Ireland (ORECNI). All participants were provided with a written explanation of the research and informed consent obtained prior to data collection. Assurances were provided regarding the confidential nature of the interview.

\section{Findings}

Various themes were derived from the interview data for this study (see Table 1).

Primary Health Care Research \& Development 2007; 8: 251-263
Table 1 Themes derived from interview transcripts

\begin{tabular}{|c|c|}
\hline Themes & Categories \\
\hline 1) Defining the role and function & $\begin{array}{l}\text { Origin of the role } \\
\text { Aspects of the role }\end{array}$ \\
\hline \multicolumn{2}{|l|}{ 2) Identifying innovation } \\
\hline \multicolumn{2}{|l|}{ 3) Qualifications and } \\
\hline \multicolumn{2}{|l|}{ 4) Sources of support } \\
\hline \multicolumn{2}{|l|}{$\begin{array}{l}\text { 5) Authority; accountability; } \\
\text { autonomy }\end{array}$} \\
\hline \multirow[t]{3}{*}{ 6) Impact of role } & Patient care \\
\hline & $\begin{array}{l}\text { Multidisciplinary } \\
\text { practice }\end{array}$ \\
\hline & $\begin{array}{l}\text { Organisational } \\
\text { practice }\end{array}$ \\
\hline 7) Nursing role or not? & \\
\hline
\end{tabular}

\section{Defining the role and function}

The post-holder was asked at the outset to describe her role and to identify what in her view made it innovative. She outlined the types of activities she undertook and the links required between primary and secondary care and with other professions:

my role is respiratory nurse specialist within a joint trust, an integrated organisation between primary and secondary care ... we would do nurse led clinics in the community and make the service more accessible to patients, advanced skills like oxygen assessment clinics and we would carry out a multidisciplinary pulmonary rehabilitation programme.

[Post-holder]

It is interesting that she used the pronoun 'we' indicating that her role depended to a large extent on interaction and collaboration with other disciplines. Additionally, the aims and objectives of the role were explored further with her line manager and the Trust's Director of Finance. This focused on the development of a specialized respiratory service specifically for patients with COPD and other chest conditions:

the aim is really to develop and deliver a more robust respiratory service within this organisation and to the patients of this area.

[Line Manager]

the aim would be to work within the sphere of an extended primary care network, 
specifically for patients with COPD and chest conditions.

[Director of Finance]

The origins of the role

The findings illustrated that the initial development of the role was a result of a number of internal and external factors. The internal factors included the practitioners (GP, pharmacist and nurse) identifying an area of need themselves.

there was a need for patients discharged in the community; ... they weren't being followed up and it was an area that the patients were being neglected. [Post-holder]

External factors identified by all interviewees included the end of GP Fundholding, the development of COPD guidelines, the development of respiratory medicine and the introduction of a managed clinical network. In fact, the line manager noted that the development of the post could be considered as:

Circumstantial in some respects as opposed to straightforward planning.

This view was echoed by the Director of Finance, who highlighted an element of risk taking in the development and initial funding of the post:

In that initial period it was very much ... let's take a risk, let's see what happens and see if we develop something.

[Director of Finance]

The line manager pointed out that at a later stage more funding became available from the Local Health and Social Care Groups (LHSCGS) for another nurse, secretarial support, physiotherapist input and specialist equipment such as blood gas analysers.

\section{Differing aspects of the role}

The post-holder's job description revealed various aspects of their role (see Figure 1). These included the provision of a pulmonary rehabilitation programme, a nurse-led assessment clinic, oxygen assessment clinic, education and training, management of the service and research. Two distinct aspects of this role were noted in the observation phase and are discussed later (see Figure 3 and Figure 4).

\begin{tabular}{l} 
Job title \\
Grade \\
Accountable to $\quad$ Director of nursing/Primary Care \\
Key Functions \\
Education/Training Remit \\
Organize and participate in teaching programmes for pre- \\
and post-registered nursing students, community staff and \\
multiprofessional groups \\
Research \\
Encourage and participate in research both in primary and \\
secondary care \\
Carry our relevant audit and research \\
Implement evidence-based practice as per Board COPD \\
strategy \\
Partnership \\
Develop partnerships with multi-agency/multi-professional \\
bodies \\
Develop a co-ordinated approach between GPS, \\
Consultants, Nurses, PAMS, Patients and Carers \\
Management remit \\
Organize caseload to provide a cost-effective and quality \\
care \\
Budget management \\
Clinical responsibilities \\
Provide a service for patients with severe COPD \\
Set up nurse-led clinics under the direction of hospital \\
Participate in health promotion in line with regional and \\
Strategic development \\
Introduce COPD care pathways \\
Establish uniformity of practice throughout the Trust \\
\hline
\end{tabular}

Figure 1 Job description

\section{Identifying innovation}

The post-holder considered one reason why her role could be considered innovative related to where she was based:

I would say my job was innovative in that I am one of the first respiratory nurses to be totally based within the community.

Her line manager concurred and expanded on the geographical nature of the role by stating that the pulmonary rehabilitation programme was based in a local leisure centre rather than a health centre/ community hospital. This was perceived as a key aspect of good practice in that while the focus was 
on chronic disease management, elements of public health and health promotion were incorporated within the role.

I think the big seller for this from a pulmonary rehab point of view is having it in a leisure centre and having nurses working in a more public health type role, as although they are still dealing with chronic disease management its ... not in an institution.

[Manager]

Innovation was also identified in terms of postholder's personal characteristics. This included the ability to network with others, motivation and striving to push forward the clinical boundaries. For example, the line manager commented:

[the Post-holder] would be fairly innovative in that she likes to push things to the edge, she's a good networker and she has linked with a lot of people.

This idea of innovation being related to the postholder's personal characteristics was also evident within some of the relevant documents related to the post. An example of this was the five-year strategic plan for the post in which the RNS had a clear vision for future developments, including the long-term goal of developing a rapid response respiratory team and a community respiratory centre.

\section{Qualifications and experience}

It was noted from the job description that the essential criteria for the post included three year's post-registration experience. This incorporated one year's experience working with COPD patients, a recognized asthma and COPD qualification, and being registered on a degree programme. The postholder met these minimum criteria, holding a BSc (Honours) in community nursing (General Practice option) along with the specialist requirements. In addition, she also held an Advanced Nurse Practitioner qualification at postgraduate level. Ongoing staff development included both in-house training, 'on the job learning' and more formal academic preparation. It was interesting to note that the advanced nurse practitioner qualification enabled the post-holder to maintain a more holistic approach

Primary Health Care Research \& Development 2007; 8: 251-263 to patient care rather than helping her to focus on her specialist area:

I think a lot of the courses can just be specialism towards lung conditions whereas the nurse practitioner course gives you a holistic approach with your skills like assessing for depression and physical examination.

[Post-holder]

Other sources of learning identified by the postholder included networking with other specialist colleagues; learning from other professionals such as physiotherapists and from different specialist nursing colleagues. Despite her acknowledgment of the beneficial aspects of formalized learning, she commented that it was the actual doing of the job that widened her understanding:

there's been a lot of learning on the ground level, learning from my colleagues and then learning and gaining clinical skills from a recognised academic qualification and then learning on the ground as you go along.

[Post-holder]

\section{Sources of support}

The post-holder identified support as coming from two sources: formal mechanisms within the Trust and informal sources outside the Trust. Formal aspects of support related to the clinical supervision sessions with the line manager once every two months. Other internal sources of support included other nursing colleagues, GPs and consultants:

I've good support from the GPs, I have a few in particular who are very supportive and the chest consultant is very supportive.

[Post-holder]

However, she commented that it was difficult to disassociate the various types of support available to her:

Its hard to separate general support from clinical support as my job is very clinically orientated.

[Post-holder]

The line manager considered that the post-holder was suitably supported for their role. However, he referred to some tensions that arose regarding 
acquiring the balance between being supportive and being her manager:

there has been one or two occasions where [the post-holder] has felt that I've been boxing her in a bit which is fine because she's challenged me about that ... so I manage her as such but at the same time I try to give her as much autonomy as I can but we know what the ground rules are.

$$
\text { [Line Manager] }
$$

\section{Authority, accountability and autonomy}

Accepting the foregoing comment from her line manager, it was clear from the interview with the RNS that she was working autonomously within and beyond a traditional nursing role:

I would go on and above the traditional nurses' role picking up things like ankle oedema and I was also trained to do a cardiac assessment.

[Post-holder]

She highlighted that she had the authority to admit patients to her caseload and to make referrals to other services. These referrals could be for a broad range of services such as mental health care, physiotherapy, occupational therapy and other specialist nursing interventions such as the tissue viability service. This authority to admit patients make referrals to other services and order specialist investigations was viewed as outside the traditional nursing role.

The post-holder commented on the difficulty with receiving inappropriate referrals from other professionals and the need to be clear about the remit of her service:

we would see ourselves as seeing the more serious patients, the more specialist patients.

[Post-holder]

She also demonstrated her autonomy through her ability to order and undertake specialist investigations. These included spirometry, lung function and blood gases based on protocols. The postholder was working very much on the boundaries of physiotherapy, and medicine and protocols were a way of negotiating role boundaries between professional groups. The post-holder considered that working in this extended role had a definite there was a patient nine months ago who one of the GPs had referred over and I went out and did an assessment, did a chest auscultation and blood gas on her and got her chest X-ray and the lady was actually in failure and needed her diuretic therapy altered and that lady with her history needed a referral to the chest consultant as she had a history suggestive of bronchiectasis and some suspicious scenario. I met her last week and she had only seen the chest consultant. So in the interim period her ankle oedema had subsided, her diuretic therapy was addressed, occupational therapy had been in and she had her perching stool and she just thought this was wonderful and we got her an ambulatory cylinder for outside the home and her quality of life had changed. ... also we looked at her dietary needs as well as her BMI was low. So we see her 9 months down the line and she had totally changed ... and it took her 9 months before she was seen by the consultant unless she put urgent on it but our chest consultant works alone and so it depends on what urgent is. So even if she had went to the consultant her OT referral wouldn't have been made and citizen's advice referral wouldn't have been made so things like that we would pick up on

Figure 2 Narrative illustrating beneficial aspects of role

advantage for patients. This is illustrated clearly in Figure 2.

In this data extract, the RNS illustrates different beneficial aspects of her role on patient care. These include (a) impact on patients' quality of life, (b) holistic assessment - with referral to dietician and occupational therapy and (c) timeliness of interventions. The issues of streamlining the referrals, reducing waiting times for the chest consultant and being able to give more time to assess each patient holistically were seen as beneficial.

If you look at it this way the consultant will spend 9 minutes at an appointment where we spend 45 minutes so we do like a holistic assessment, and even psychologically spending that time, the consultant doesn't have that time, we can give so much more time and filter in all the other disciplines as well.

[Post-holder]

\section{Post-holders perceived impact of role}

The perceived impact of the role was considered from various perspectives such as patient care, multidisciplinary practice and organizational practice.

Primary Health Care Research \& Development 2007; 8: 251-263 


\section{Impact on patient care}

All of the participants identified various perceived benefits of the role on patient care including a holistic service, availability of the service, building good relationships with patients and improved quality of life through therapeutic approaches:

You're providing an holistic service to patients and you are there at the end of a phone which they can contact. [Post-holder]

In commenting on the perceived benefit for the pulmonary rehabilitation programme the line manager stated:

I suppose the problem for chronic diseases and respiratory especially is people think, 'this is me, I'm on the scrap heap' type thing and I think what I've seen is that they all of a sudden start to get a spark again, they are going through a programme where everything is measured and they can see their achievements, the outcomes are there, but for a guy to be able to play another couple of holes of golf is tangible. [Line Manager]

\section{Perceived impact on multidisciplinary practice}

A big impact of the role was the development of multidisciplinary team working. This was at odds with the idea of having a nurse-led service and was something that all the participants were keen to emphasize:

The big seller for this is multidisciplinary working ... and its still seen as nursing led and all the rest of it, it may be nursing led but physio's a key person in there and is part of the team and we need it. [Line Manager]

\section{Perceived impact on the organization}

Both the line manager and Director of Finance noted that the role had an impact on the larger organization in terms of promoting integration and developing organizational relationships. This was clearly beneficial within the context of an integrated acute and community health care organization.

I actually think taking COPD aside, I think this particular role has been essential because running in parallel to this was a combination of acute and community organisation and hem. ... that size of organisational change is difficult for some people to manage and one of the key things we have to get right are organisational relationships and crosssectoral and cross boundary workings and very early on [Post-holder] was able to go into the hospital to build bridges.

[Director of Finance]

\section{Nursing or not?}

Although both the post-holder and line manager acknowledged that the specialist nurse role extended beyond traditional nursing boundaries, they both noted that the role was still essentially nursing.

I think it is an expansion of a nursing role because I don't think a physiotherapist could come in and do my job because of my background and I do think my nursing skills are very important ... and I think its something nurses do very well and it shouldn't be another discipline.

[Post-holder]

I think the role is very clearly a nursing role, they are doing some things that I suppose were really medical at one time like the blood gas analysis and near patient testing that's pushing the boundaries a bit further. I see it as a nursing thing and a more holistic approach so it's not just the clinical stuff but also the social stuff and trying to bring all that together.

[Line Manager]

\section{Non-participant observation data}

Non-participant observation of the post-holder also supported the nursing focus of the role. This is illustrated in the following case studies (Figure 3 and Figure 4), which reported on two different elements of observed practice. The observation of the nurseled assessment clinic (Figure 3) highlighted aspects of a holistic nursing assessment. In this scenario not only was it important for the nurse to be able to provide treatment for breathlessness but also to provide education, support, onward referral and a future plan of action. It was the combination of these factors that provided both physical and psychological relief for the patient, indicating the specialist nurse's interpersonal and technical skills. The second observation, relating to the pulmonary 
A patient attends the nurse-led clinic for assessment. The man enters the room extremely distressed and breathless and he tells the story of how he had to attend the local $A$ and $E$ department the previous night owing to his breathlessness. Whilst he was at the hospital he received a steroid injection, nebulizer treatment and oral steroids. At this stage in the consultation the man stated he couldn't go on like this and he wanted the nurse to do 'anything, something' for him. The nurse reassures the patient that she will try and help him and then commences various investigations. These include chest auscultation, spirometry, lung function tests; reversibility testing, inhaler technique testing and checking his blood pressure. She then commenced the patient on a nebulizer during the consultation. Having helped to relieve the patient's immediate distress and breathlessness the nurse then carries on with her assessment using a specially designed assessment sheet. The nurse provided the patient with both verbal and written information on his inhalers and made a referral to the GP for some changes. Then the nurse discussed the pulmonary rehabilitation programme with the patient. This had been suggested previously to this patient but he had refused. During this consultation he agreed to the referral to the physiotherapist for assessment for the programme. The consultation with this patient lasted forty-five minutes and what was most noteworthy was the transformation in the patient. The patient stated that he felt much better physically after attending and that he felt better in himself (psychologically) in that he was willing to try the pulmonary rehabilitation programme which could potentially improve his quality of life.

Figure 3 Nurse-led assessment clinic

This involved accompanying the nurse on her twice weekly pulmonary rehabilitation programme based in a local leisure centre. Eight patients attended along with another two RNSs and a physiotherapist. Each patient had their own individual programme and they were involved in the completion of their own documentation. A good relationship was noted between the nurses and physiotherapist involved in the programme. It was also observed that the patients had developed not only a good relationship with the professionals but also a good support with each other. This particular programme was nearing its completion and so the patients were asked if they would like to move into the next phase of the chair-based exercise programme or use other facilities in the leisure centre. The nurse went and spoke with the manager of the leisure centre who then came and gave the patients a tour of the leisure centre. What was noteworthy during this observation was the relationship building taking place between the patients themselves and between the different professionals and sectors (ie, the nurse, physiotherapist and leisure centre staff).

Figure 4 Pulmonary rehabilitation programme rehabilitation programme, highlighted other aspects of the specialist nurse role (Figure 4). These included multidisciplinary and integrated work practices associated with advanced nursing roles.

\section{Discussion}

The recognition of the severity and public burden of respiratory diseases and long-term conditions has provided impetus for the development of services commonly led by RNSs. It has been acknowledged that pro-active disease management can make a real difference to patients (Department of Health, 2006). Whilst the literature surrounding the RNS role is limited and debate exists regarding its value (Griffiths et al., 2004; Taylor et al., 2005) there are some examples of how the RNS has led to improved outcomes for patients. These included improved clinical competence (Ketelaars et al., 1996), improved quality of life ratings (Sharples et al., 2002), a reduction in unscheduled care for asthmatic patients (Griffiths et al., 2004), and safe and effective follow up for patients admitted to hospital with asthma (Laroche, 2005). The findings from the present study also provide some evidence for the impact and value of the role of the RNS on patient care, multidisciplinary and organizational practice. It was found that the postholder was working as an autonomous practitioner, managing her own caseload, linking the primary and secondary care interface, and providing a key role in facilitating patient care. The development of this advanced role provided the opportunity to broaden nursing skills whilst at the same time meeting patients' needs. Although some of the duties undertaken by the post-holder could have been viewed as outside the traditional role of the nurses, these aspects reflect many of the specialist nurse role components previously identified by Wilson-Barnett and Beech (1994), such as education and training, the organization of care and research.

The findings also indicated perceived positive outcomes of this role on service provision. These included the provision of holistic care, multidisciplinary working, developing appropriate referrals to specialists and quicker initiation of treatment. The development of multidisciplinary working is reflected in the Department of Health's (1996) call

Primary Health Care Research \& Development 2007; 8: 251-263 
for seamless care, which should contain the following factors:

1) Organizational boundaries that do not stand in the way.

2) Practitioners with clear roles, responsibilities and accountability.

3) The use of multiprofessional teams.

4) Support in working across organizational boundaries.

This post-holder could be seen to have incorporated all these elements within her practice, working towards the integration of patient care. This can be seen to reflect the recent policy documents (Department of Health, 2004) associated with chronic disease management incorporating selfmanagement, disease management and care management. However, whilst partnership is central to the development of innovative roles and interprofessional working is recommended (Department of Health, 2000; Fitzgerald et al., 2003), we are warned that one consequence may be the blurring of professional roles (Castledine, 2003).

The literature also indicates that the innovative nature of some roles can mean that accessibility to colleagues in similar roles is difficult, limiting opportunities to discuss professional and practice issues, or identify possible mentors (Levenson and Vaughan, 1999). This did not seem to be the case for this post-holder. It was noted, however, that the post-holder's line manager identified tensions between being supportive and being a manager. This finding highlights inherent difficulties between allowing the post-holder freedom and autonomy, and yet maintaining some management structure. A contributing factor may be the sense of this post-holder sitting outside of the usual management structures. It needs to be acknowledged that this could have the potential to lead to role conflict, with some divergence between the role expectations among different members of the role set (ie, the manager and the post-holder) (Bower et al.,2004). A number of studies have warned about the consequences of a lack of support leading to isolation and burnout (Scholes et al., 1999; Wilson-Barnett et al., 2000; Ewens, 2003).

It was noted that the initial development of the role was not planned but was based on number of internal and external stimuli such as a recognized gap in service provision and the development of Primary Health Care Research \& Development 2007; 8: 251-263
COPD guidelines. This lack of planning and the idea of risk taking in the development of the role concurs with Castledine (2003) who noted that many of the first nurse specialist roles were developed without clear direction or control. In addition, the influence of external factors such as waiting list initiatives (Read et al., 2001), patient demands (Daly and Carnwell, 2003), nurse prescribing (Last and Self, 1994), junior doctors' working hours (Buchan and Seccombe, 2003; Cameron and Masterson, 2000) and interagency and inter-professional working (Department of Health, 2000; Fitzgerald et al., 2003) on the development of 'innovative' nursing roles has been acknowledged.

The findings from the study indicated that the post-holder had a wealth of previous respiratory experience and specific skills and qualifications for the post. Although the post-holder considered that the training received to date was relevant and helped to increase her credibility in the eyes of patients and other health professionals, she acknowledged the value of learning on the job and working with other members of the multidisciplinary team. This confirms Wooler's (2001) claims that practitioners are seeking training from medical colleagues and in-house training sessions. However, the need for education and training for the development and enhancement of new roles to ensure quality has been recommended (Scottish Office, 1995). The personal attributes of the postholder were also identified as a key factor influencing the success of the post, helping to increase networking and acceptance of the role across clinical boundaries. The importance of personal attributes has previously been identified as vital to the success and acceptance of such roles in a similar study exploring the role of an outreach oncology nurse practitioner (McKenna et al., 2004).

With regards to innovative aspects of the role it was noted that these included community-based multidisciplinary teamwork working across organizational boundaries, co-ordinating packages of care and increasing the accessibility of services for patients. It was also interesting to note that a 'novel' or innovative aspect of the role in this case study was its geographic location in a communitybased leisure centre rather than in an acute hospital setting. One would have perhaps expected the innovative nature of the role to be focused upon nurses undertaking new care practices and 
therapeutic interventions that improved the outcome for patients. That this was not highlighted may be due to the nurse and her line manager perceiving what the nurse was doing to be simply normal practice. Their focus on the geographic location of the post may be explained by the findings from a recent study by the British Lung Foundation and British Thoracic Society (2003) which revealed that only $9 \%$ of all pulmonary rehabilitation is carried out in the primary care setting. It has been recognized that delivering improvements in primary care is a key priority of the NHS plan (Department of Health, 2000). Additionally, this innovative aspect was even further enhanced through basing this programme within a leisure centre in what can be considered as a health-orientated environment. It could be argued that by changing the context in which this programme was delivered helped to change the focus from merely disease management to include a public health dimension. Cockcroft et al. (1987), however, indicate that whilst such an approach to care is beneficial it could be costly to the health service. The importance of public health has been further emphasized in the frameworks for planning and delivering community health nursing in the UK (Department of Health, 2002) and Northern Ireland (DHSSPS, 2003).

\section{Limitations}

This study has a number of limitations. Firstly, the views of members of the multidisciplinary team and patients were not recorded. It is recommended that further research should be undertaken to collect the views and experiences of both patients and multiprofessionals with regards to the RNS role. Secondly, due to the individuality of the role and the case study approach adopted, participants were known to one another and this may have caused bias. Finally, the single case study approach adopted limits the generalizability of the findings.

\section{Conclusion}

Change and innovation is happening in community health nursing practice to meet the changing needs of society. The RNS role is characterized by the provision of unique care that is comprehensive, efficient and accessible. The findings from this case study illustrate the value and potential for nurses to lead and co-ordinate the provision of a respiratory service to patients. The study also depicts a clear example of an innovative role in nursing in terms of the role context, the skills and knowledge required, the personal characteristics of the post-holder and the impact on multidisciplinary integrated working. There is always some debate as to whether new roles remain within the discipline of nursing or cross the boundaries to other disciplines such as medicine and physiotherapy. However, it was evident from the interviews and observation in practice that although the RNS used different skills to enhance her practice she still employed these skills in a nursing context. Furthermore the findings of this paper are relevant for both health care professionals and health care managers with an interest in establishing comparable services.

\section{Acknowledgements}

The authors would like to thank the Northern Ireland Practice Education Council for Nursing and Midwifery (NIPEC) for funding this project.

\section{References}

Bower, P., Jerrim, S and Gask, L. 2004: Primary care mental health workers: role expectations, conflict and ambiguity. Health and Social Care in the Community 12,336-40.

British Thoracic Society and British Lung Foundation. 2003: Pulmonary rehabilitation survey. London: British Thoracic Society.

British Thoracic Society Standards of Care Subcommittee on Pulmonary Rehabilitation. 2001: Pulmonary rehabilitation BTS statement. Thorax 56, 827-34.

Buchan, J. and Dal Poz, M. 2002: Skill mix in the health care workforce: reviewing the evidence. Bulletin of the World Health Organisation 80, 575-80.

Buchan, J. and Seccombe, I. 2003: More nurses working differently? A review of the UK nursing labour market 2002 to 2003. London: RCN.

Burnard, P. 1991: A method of analysing interview transcripts in qualitative research. Nurse Education Today 11, 461-66.

Burnard, P. 1996: Teaching the analysis of textual data: an experiential approach. Nurse Education Today 16, 278-81.

Cameron, A. and Masterson, A. 2000: Managing the unmanageable? Nurse Executive directors and the new role in nursing. Journal of Advanced Nursing 31, 1081-88. 
Castledine, G. 2003: Generalist and specialist nurses - complementary or conflicting roles? Edinburgh: Scottish Executive.

Chang, K.P.K. and Wong, K.S.T. 2001: The nurse specialist role in Hong Kong: perceptions of nurse specialists, doctors and staff nurses. Journal of Advanced Nursing 36, 32-40.

Cockcroft, A., Bagnall, P., Heslop, A., Andersson, N., Heaton, R., Batstone, J., Allen, J., Spencer, P. and Guz, A. 1987: Controlled trial of respiratory health worker visiting patients with chronic respiratory disability. British Medical Journal 294, 225-28.

Daly, W.M. and Carnwell, R. 2003: Nursing roles and levels of practice: a framework for differentiating between elementary, specialist and advancing nursing practice. Journal of Clinical Nursing 12, 158-67.

Denzin, N.K. 1989: The Research Act, third edition. New Jersey Englewood Cliffs: Prentice Hall.

Department of Health. 1996: Primary care: the future. London: Department of Health.

Department of Health. 2000: The NHS Plan - a plan for investment, a plan for reform. London: HMSO.

Department of Health. 2002: Liberating the Talents. London: Department of Health.

Department of Health. 2004: Improving chronic disease management. London: HMSO. Retrieved 12 October 2005 from http://www.dh.gov.uk/PublicationsAndStatistics/Publicatio ns/PublicationsPolicyAndGuidance/PublicationsPolicyAnd GuidanceArticle/fs/en?CONTENT_ID=4075214andchk= YxS1Yj.

Department of Health. 2006: National Service Framework for Chronic Obstructive Pulmonary Disease. London: Department of Health.

Department of Health, Social Services and Public Safety. 2003: Strategic Direction in Community Nursing in Northern Ireland: Position Paper. Belfast: DHSSPS.

Ewens, A. 2003: Changes in nursing identities: supporting a successful tradition. Journal of Nursing Management 11, 224-28.

Fitzgerald, L., Ewan, F. and Hawkins, C. 2003: Innovation in healthcare: how does credible evidence influence professionals? Health and Social Care in the Community 11, 219-28.

Griffiths, C., Foster, G., Barnes, N., Eldridge, S. Tate, H., Begum, S., Wiggins, M., Dawson, C., Livingstone, A., Chambers, M., Coats, T., Harris, R. and Feder, G. 2004: Specialist nurse intervention to reduce unscheduled asthma care in a deprived multiethnic area: the east London randomised controlled trial for high risk asthma (ELECTRA). British Medical Journal 328, 144-47.

Horrocks, S., Anderson, E. and Sailsbury, C. 2002: Systematic review of whether nurse practitioners working in primary care can provide equivalent care to doctors. British Medical Journal 324, 819-23.

Jamieson, L. and Williams, L.M. 2002: Confusion prevails in defining advanced nursing practice. Collegian 9, 29-33.

Kendall, L. and Lissauer, T. 2003: The future health worker. London: IPPR.

Primary Health Care Research \& Development 2007; 8: 251-263
Ketelaars, A.J.C., Abu-Saad, M.H., Halfens, J.G.R., Schlosser, M., Mostert, R. and Wouters, E. 1996: Quality of care of patients with chronic obstructive pulmonary disease provided y specialised community nurses: a process evaluation. Health and Social Care in the Community 4, 200-207.

Lambert, V.A. and Lambert, C.E. 2001: Literature review of role stress/strain on nurses: an international perspective. Nursing and Health Sciences 3, 161-72.

Laroche, C. 2005: Follow up of patients admitted to hospital with asthma: best performed by specialist nurse or doctor? The Research Findings Seminar, Summary paper 1402. Retrieved 12 October 2005 from http://www.ReFeR.nhs.uk/ ViewRecord.asp?ID =1402.

Last, T. and Self, N. 1994: The expanded role of the nurse in intensive care. In Hunt, G. and Wainwright, P., editors, Expanding the Role of the Nurse. The Scope of Professional Practice. Oxford: Blackwell Scientific Publications.

Levenson, B. and Vaughan, B. 1999: Developing new roles in practice: an evidence based guide. Sheffield: University of Sheffield.

Lung Asthma Information Agency 2001: Trends in Emergency Hospital Admissions for Lung Disease. London: Lung Asthma Information Agency. Retrieved 19 August 2005 from http:// www.laia.ac.uk/2001_4/2001_4.htm.

Madonna, M.G. and Keating, M.M. 1999: Multiple Sclerosis pathways: an innovative nursing role in disease management. Journal of Neuroscience Nursing 31, 332-35.

McKenna, H., Keeney, S. and Bradley, M. 2003: Generic and specialist nursing roles in the community: an investigation of professional and lay views. Health and Social Care in the Community 11, 537-45.

McKenna H., McCann, S., McCaughan, E. and Keeney S. 2004: The role of an oncology outreach nurse practitioner: a case study evaluation. European Journal of Oncology Nursing 8, 66-77.

McKenna, H.P., Richey, R., Sinclair, M., Poulton, B., Keeney, S. and Hasson, F. 2005: An exploration of innovative nursing and midwifery roles within Northern Ireland's HPSS. Belfast: NIPEC.

Mills, N., Campbell, R. and Bachman, M.O. 2002: Professional and organisational obstacles to establishing a new specialist service in primary care: case study of an epilepsy specialist nurse. Journal of Advanced Nursing 37, 43-51.

Nkowane, A.M. and Saxena, S. 2004: Opportunities for an improved role for nurses in psychoactive substance use: Review of the literature. International Journal of Nursing Practice 10, 102-10.

Nolan, P., Bourke, P. and Doran, M. 2002: UK and USA Clinical Mental Health Specialists' perceptions of their work. Journal of Psychiatric and Mental Health Nursing 9, 293-300.

Pearson, A. 2003: Key Performance indicators for nursing. International Journal of Nursing Practice 9, 337.

Rafferty, S. and Elborn, J.S. 2002: Do nurses do it better? Thorax 57, 659-60.

Read, S., Lloyd Jones, M., Collins, K., McDonnell, A., Jones, R., Doyle, L., Cameron, A., Masterson, A., Dowling, S., 
Vaughan, B., Furlong, S. and Scholes, J. 2001: Exploring new roles in practice: implications of developments within the clinical team (ENRiP). School of Health and Related Research (ScHARR). Sheffield: University of Sheffield. Retrieved 12 October 2005 from http://www.shef.ac.uk/ content/1/c6/01/33/98/enrip.pdf.

Ross, J. 1999: The development of the advanced role of rural nurses in New Zealand. Australian Journal of Rural Health 7,253-57.

Scholes, J., Furlong, S. and Vaughan, B. 1999: New roles in practice: charting three typologies of role innovation. Nursing in Critical Care 4, 268-75.

Scottish Office Department of Health. 1995: Health Service Developments and the Scope of Professional Nursing Practice: a survey of developing clinical roles within NHS Trusts in Scotland. Scotland: National Nursing, Midwifery and Health Visiting Advisory Committee.

Sharples, L.D., Edmunds, J., Bilton, D., Hollingworth, W., Caine, N., Keogan, M. and Exley, A. 2002: A randomised controlled trial of nurse practitioner versus doctor led outpatient care in a bronchiectasis clinic. Thorax 57, 661-67.

Stake, R.E. 1995: The art of case study research. California: Sage Publications.
Taylor, S., Candy, B., Bryar, R., Ramsey, J., Vrijhoef, H., Esmond, G., Wedzicha, J. and Griffiths, C. 2005: Effectiveness of innovations in nurse led chronic disease management for patients with chronic obstructive pulmonary disease: systematic review of evidence. British Medical Journal 331, 485-88.

Turner, C. and Keyzer, D. 2002: Nurse practitioner: a contract for change and excellence in nursing. Collegian 9, 18-23.

Wilson-Barnett, J. and Beech, S. 1994: Evaluating the clinical nurse specialist: a review. International Journal of Nursing Studies 31, 561-71.

Wilson-Barnett, J., Barriball, K.L., Reynolds, H., Jowett, S. and Ryrie, I. 2000: Recognising advancing nursing practice: evidence from two observational studies. International Journal of Nursing Studies 37, 389-400.

Wooler, E. 2001: The role of the nurse in paediatric asthma management. Paediatric Respiratory Reviews 2, 76-81.

World Health Organization. 2002: Integrating prevention into healthcare. Fact Sheet No. 172, October, Geneva: WHO. Retrieved 12 October 2005 from http://www.who.int/ mediacentre/factsheets/fs172/en/.

Yin, R. 1994: Case study research: design and methods. Second edition, California: Sage. 